\title{
VALIDATION OF URDU VERSION OF CENTER FOR EPIDEMIOLOGICAL STUDIES FOR DEPRESSION SCALE FOR CHILDREN IN CONTEXT OF PAKISTAN
}

\author{
Nazia Mustafa, Aneela Maqsood \\ Fatima Jinnah Women University, Rawalpindi Pakistan
}

\begin{abstract}
Objective: To translate and psychometrically validate the center for epidemiological studies for depression scale (CES-DC) for Pakistani children.

Study Design: Cross-sectional study.

Place and Duration of Study: Various schools in Rawalpindi, from Feb to Mar 2021.

Methodology: Present study comprised of translation, cross-language validation and investigation of psychometric properties of the scale into Urdu Language. Urdu translated version and strength and difficulty questionnaire were administered on 154 primary school children from various private schools situated in Rawalpindi district. Cronbach's alpha reliability, item-total correlation and Pearson's correlation coefficient were used for analysis.

Results: Results revealed that this scale had good internal consistency and reliability (Urdu-version $a=0.73$; English-version $\mathrm{a}=0.65$ ) along with correlation coefficients over a period of 15 days ( $\mathrm{r}=0.96)$. Cronbach's alpha value of scales was found to be fairly high $(\mathrm{r}=0.78$ and $\mathrm{r}=0.81)$. Item-total correlation of translated scale was also satisfactory (ranged from $0.04-0.58)$ and Pearson's correlation of translated version with strength and difficulty questionnaire indicated good convergent validity $(\mathrm{r}=$ $0.54 ; p<0.01)$.

Conclusion: Results supported the feasibility, reliability and validity of the Urdu version of this scale to screen depression among Urdu speaking pediatric Pakistani population.
\end{abstract}

Keywords: Childhood depression, Psychometrics, Validation of diagnostic measures.

How to Cite This Article: Mustafa N, Maqsood A. Validation of Urdu Version of Center for Epidemiological Studies for Depression Scale for Children in Context of Pakistan. Pak Armed Forces Med J 2021; 71(6): 2019-2023. ～Doi: https://doi.org/10.51253/pafmj.v6i6.7428

\footnotetext{
This is an Open Access article distributed under the terms of the Creative Commons Attribution License (https://creativecommons.org/licenses/by-nc/4.0/), which permits unrestricted use, distribution, and reproduction in any medium, provided the original work is properly cited.
}

\section{INTRODUCTION}

Depression is most common and highly prevalent mental health issue all over the world. According to World Health Organization (WHO), more than 264 million people agonize from depression by contributing significantly to the overall global burden of disease. ${ }^{1}$ Children growing up in present era are also vulnerable for the development of mental health issues. ${ }^{2}$ Specially, depressive disorders are no more problems of only adulthood rather have their roots in childhood and adolescents. ${ }^{3}$ Depression is common with several other psychiatric disorders i.e., anxiety and many risks in adulthood. ${ }^{4}$ Recent studies revealed that approximately $946.7 \%$ of children suffer from anxiety and comorbid depressive symptoms. ${ }^{5}$ If these conditions are not addressed timely, they tend to become chronic and increase risk of consequent mental health problems later in life. ${ }^{6}$ Unfortunately, very few children with mental health problem get detected and actually receive treatment because of the scarcity of appropriate screening tools.

Correspondence: Dr Nazia Mustafa, Flat No. C, Block E-15, General Javed Sultan, Shaheed Colony Road, Rawalpindi Pakistan

Received: 25 Sep 2021; revision received: 12 Nov 2021; accepted: 22 Nov 2021
Similar to the other developing countries, Pakistan has experienced various political, social, and cultural vicissitudes which pose serious implications on the development and wellbeing of young children and adolescents. However, only few studies have been done to explore the childhood psychological problems and have estimated that $10-19 \%$ of children fall into an abnormal range of socio-emotional problems (both internalizing and externalizing). ${ }^{7,8}$ This emphasized the significance of a reliable and valid screening measure for the early identification of depressive symptoms among children. It will also help in the selection of a suitable intervention.

Centre for epidemiologic studies depression scale for children (CES-DC) is one of the most widely used childhood depression scales. ${ }^{9}$ In present study, it was selected to translate into Urdu, because of its several characteristics which make it a useful scale for screening depression among children in Pakistan. Firstly, CES-DC is most extensively used self-report scale for measuring depressive symptoms among young children. Secondly, the CES-DC is a brief, simple and extremely user-friendly scale. Thirdly, the CES-DC is in public domain which can be used without incurring 
any expense. It already has been translated in several languages with good reliability and validity. ${ }^{10}$ Extensive literature review revealed no such work has been done in Pakistan on the translation of the CES-DC. So present study was designed with the objective of translation and cross-language validation/psychometric validation of CES-DC for Pakistani pediatric population.

\section{METHODOLOGY}

Present study was based on the cross-sectional research design in which primary school children were recruited from various private schools located in Rawalpindi District, from February to March 2021 through the random sampling. One school system was selected randomly from the list of all the schools in Rawalpindi regions. After that, all schools of that system was included in the sub-list and two schools were selected again from the list randomly. All children of 5 th class from two school were included in the study.

Inclusion Criteria: Students of grade 5 with age range 10-12 years of age who can read and write Urdu language easily were included in the study.

Exclusion Criteria: Students with some serious physi$\mathrm{cal} /$ medical diseases; serious mental health issues, having psychological treatment; had some surgery or serious traumatic event in past 6 months and those unwilling to participate were excluded from the study.

The sample size was appropriate as past validation studies recommended that 5-10 participants per scale item are considered suitable to calculate the sample size. In present study, total no of items of CES-DC were 20 and ratio of 5 participants per item was taken. Which suggested 100 participants for the validation of scale, so all 154 participants selected from two schools were enrolled in the study. ${ }^{11}$

The study was carried out by multi-level procedural steps along with due ethical consideration at every stage. Before the start of study, researcher got formal permission for translation from the author of scale through email and approval from the Academic Studies and Research Board (ASRB), Fatima Jinnah Women University (ASRB NO FJWU/EC/2021/32). The study encompassed of two phases (1) pilot phase was aimed at translation of the scale and its cross-language validation (2) main study phase deals determination of psychometric properties of the translated version. During the pilot phase, the Standard method of back translation was used to examine the cross-language validation. ${ }^{12}$ A panel of five bilingual experts with level degrees in psychology did five independent forward translations of the scale. Urdu translated versions were reconciled by a committee of subject matter experts (SME) comprising of 5 experts with Masters, MPhil and $\mathrm{PhD}$ degrees in psychology. Final Urdu version was translated back into English language to determine the authenticity of translated scale by five bilingual experts independently. These bilinguals were neither familiar with the content of the original scale nor included in the forward translation process. Same committee of experts who initially finalized the forwarded translation, critically analyzed back translated items and finalized the items of Urdu versions.

In the end, cross-language validation was done by administering the Urdu translated version and the original English version of the scale on the sample of 30 students. They were divided into 2 groups (each group consisting of 15 participants); one group was given the Urdu translated version and other group was given original English versions of scale. This procedure was repeated on the same participants after a gap of 15 days. The purpose of the cross-language validation is to ensure the structural and empirical equivalence of the Urdu translated version with the original English version. After permission from all concerned stakeholders 160 students based on the inclusion criteria were selected. Their verbal consent along with written ascent was taken from them. With the help of school's administration, parents were contacted, briefed about research propose/procedures and their written consent was obtained. Six parents refused to participate in the study, so finally 154 students were enrolled.

Scales were administered through group administration method in which children were provided with assessment Pack (Socio-demographic form, Translated Urdu version of CES-DC and Strength and Difficulties Questionnaire (SDQ) Urdu version) and detailed instructions were given to them.

Brief detail of instruments of assessment pack included 'socio-demographic form' was comprised of age, gender, grade level, no of siblings, Birth order, parent's level of education, socioeconomic status (SES) (such as income and education) and family setup). CES-DC is a 20 item, 4-point Likert self-report scale for the screening of depressive symptoms in children and adolescents of age 6- 17 years where 0 indicates "not at all", 1 indicates "a little", 2 indicates "some" and 3 indicates "a lot". Four items $(4,8,12,16)$ are scored in the reversed order to control for response bias. A cut-off score of 15 is suggestive of depressive 
symptomatology in children and adolescents. It is in public domain with good psychometric properties. ${ }^{13}$ SDQ is a 25-item, 3-point Likert, self-report scale for general difficulties (emotional and behavioral) and positive behaviors of children aged 3-16 years, where 0 is "Not true", 1 is "Somewhat true" and 2 is "certainly true". Total scores in each subscale ranges from 0-10 with higher scores showing more difficulties. It has 5 subscales each with 5 items; emotional symptoms scale which includes anxiety and depressive symptoms (items 3,8,13,16,24), conduct problem scale (items 5,7, 12,18,22), hyperactivity/inattention scale (items 2,10, $15,21,25)$, peer relationship problem Scale items 6,11, $14,19,23$ ) and Prosocial behaviour Scale (items 1,4,9,17). It has good psychometric properties $(\mathrm{r}=0.80) .{ }^{14}$ Strengths and difficulties questionnaire (SDQ) Urdu version emotional symptoms subscale was used in this study which has good Cronbach's alpha $(r=0.70) .{ }^{15}$

Researchers read each statement to them and they were asked to fill the relevant columns along with the assistance of class teacher and research assistant. It was made sure that the obtained information would only be used for the research purpose and kept confidential. Furthermore, various ethical issues are important to consider while conducting research with the children for their protection. Researchers really took care of the principles of beneficence and non-malfeasance, highlighting the craving to protect children from any type of harm. It was made sure that for any potential risks related to emotional disturbance, referrals to mental health professionals would be made. The data were analyzed in terms of descriptive statistics, Pearson correlation, item-total correlations, alpha reliability and convergent validity by using Statistical Package for Social Sciences (SPSS version 26).

\section{RESULTS}

Results revealed that this scale had good internal consistency and reliability (Urdu-version $\alpha=0.73$; English-version $\alpha=0.65$ ) along with correlation coefficients over a period of 15 days $(r=0.96)$. Cronbach's alpha value of scales was found to be fairly high ( $\mathrm{r}=0.78$ and $\mathrm{r}=0.81$ ). Item-total correlation of translated scale was also satisfactory (ranged from 0.04-0.58) and Pearson's correlation of translated version with strength and difficulty questionnaire indicated good convergent validity $(\mathrm{r}=0.54 ; p<0.01)$.

In the pilot phase, sample of 30 students including 17 (56.6\%) boys and $13(43 \%)$ girls of class 5th with age range 10-12 years was approached. Whereas, in main study, the sample encompassed of 154 chil- dren/students with age range 10-12 years (10.86 \pm 0.62$)$ including $92(59.7 \%)$ boys and $62(40.3 \%)$ girls. Detailed results are narrated below.

Table-I shows that Cranach's alpha coefficient was 0.79 for Urdu Version; 0.77 for English version and the test re-test reliability correlation of $r=0.99$. This indicated that Urdu CES-DC had a good internal consistency and test-retest reliability over the period of 15 days in a sub-sample of 30 students.

Table-I: Pearson product-moment correlation coefficient, testretest reliability of both Urdu and English versions of CESDC $(n=30)$.

\begin{tabular}{l|c|c|c|c}
\hline CES-DC & $\begin{array}{c}\text { Test } \\
\text { (Urdu) }\end{array}$ & $\begin{array}{c}\text { Retest } \\
\text { (English) }\end{array}$ & $\begin{array}{c}\text { Correlation } \\
\text { Coefficients }\end{array}$ & $\begin{array}{c}p \text { - } \\
\text { value }\end{array}$ \\
\cline { 1 - 3 } Mean \pm SD & $14.83 \pm 7.94$ & $15.20 \pm 7.54$ & & \\
\cline { 1 - 3 } Range & $0-60$ & $0-60$ & \multirow{2}{*}{0.99} & 0.001 \\
\cline { 1 - 2 } $\begin{array}{l}\text { Item-total } \\
\text { correlation }\end{array}$ & $0.15-0.77$ & $0.06-0.74$ & & \\
\cline { 1 - 3 } $\begin{array}{l}\text { Alpha } \\
\text { Reliabilities }\end{array}$ & 0.79 & 0.77 & & \\
\cline { 1 - 3 }
\end{tabular}

CES-DC $=$ The center for epidemiological studies depression scale for children

Table-II shows that pilot study's sample comprised of $92(59 \%)$ boys and $62(40.3 \%)$ girls; among them $42(27.3 \%)$ were of age 10 years old, $92(59.7 \%)$ were of 11years old and $20(13 \%)$ were of 12 years old further to it, $79(51.3 \%)$ children were living in joint family setup and $75(48.7 \%)$ were living in nuclear family setup. Majority of children's parents had graduation level education \{fathers with graduation level educatio 80 $(51.9 \%)\}$ and family income range of 50000 rupees to 100000 rupees was 98 (63.6\%).

Table-II: Demographics profile of sample $(n=154)$.

\begin{tabular}{l|c}
\hline \multicolumn{1}{l}{ Demographics } & $\mathbf{n}(\mathbf{0})$ \\
\hline Gender & $92(59.7)$ \\
\hline Boy & $62(40.3)$ \\
\hline Girl & $42(27.3)$ \\
\hline Age & $92(59.7)$ \\
\hline 10 Years & $20(13)$ \\
\hline 11 Years & $26(16.9)$ \\
\hline Father's Education & $80(51.9)$ \\
\hline Matric and below & $47(30.5)$ \\
\hline Matric-Graduation & $26(16.9)$ \\
\hline Graduation and above & $93(60.4)$ \\
\hline Mother's Education & $35(22.7)$ \\
\hline Matric and below & $37(24)$ \\
\hline Matric-Graduation & $98(63.6)$ \\
\hline Graduation and above & $19(12.3)$ \\
\hline Family Income & $75(48.7)$ \\
\hline 50000 rupees and below & $79(51.3)$ \\
\hline 10000 rupees to 100000 rupees rupees and above &
\end{tabular}


Table-III shows item-total correlation of CESDC$\mathrm{U}$. Most of the items were in the range of 0.04 to 0.58 , which was acceptable. However, two items (item no 4 and 8 ) had less than 0.3 item total correlations.

Table-III: Item total correlation of CES-DC ( $\mathrm{n}=154)$.

\begin{tabular}{c|c}
\hline Items Numbers of the CSS-DC & Item Total Correlation \\
\hline 1 & 0.39 \\
\hline 2 & 0.39 \\
\hline 3 & 0.55 \\
\hline 4 & 0.12 \\
\hline 5 & 0.50 \\
\hline 6 & 0.58 \\
\hline 7 & 0.49 \\
\hline 8 & 0.04 \\
\hline 9 & 0.50 \\
\hline 10 & 0.55 \\
\hline 11 & 0.37 \\
\hline 12 & 0.45 \\
\hline 13 & 0.56 \\
\hline 14 & 0.45 \\
\hline 15 & 0.57 \\
\hline 16 & 0.35 \\
\hline 17 & 0.55 \\
\hline 18 & 0.46 \\
\hline 19 & 0.53 \\
\hline 20 & 0.52 \\
\hline &
\end{tabular}

Table-IV presents alpha reliabilities of research instruments. The alpha reliability of the CES-DC-U was 0.78 and of the SDQ- U was 0.81 , which means reliability was fairly high and scales was reliable.

Table-IV: Alpha Reliability Coefficient of CES-DC-U and SDQ-U (n=154).

\begin{tabular}{l|c|c}
\hline $\begin{array}{l}\text { Subscales/ } \\
\text { Composite }\end{array}$ & No. of Items & $\begin{array}{c}\text { Alpha } \\
\text { Coefficients }\end{array}$ \\
\hline CES-DC & 20 & 0.78 \\
\hline SDQ & 25 & 0.81 \\
\hline
\end{tabular}

Table-V presents Pearson product moment correlation between CESDC-U and SDQ-U, emotional symptoms subscale indicated good correlation $(\mathrm{r}=0.54$; $p<0.01)$ which was support for its convergent validity.

Table-V: Pearson product moment correlation between CESDC-U and SDQ-U ( $n=154)$.

\begin{tabular}{l|c|c}
\hline Scales & SDQ-U & $p$-value \\
\hline CESDC-U & $\mathrm{r}=0.54$, & $<0.001$ \\
\hline
\end{tabular}

\section{DISCUSSION}

Present study was designed with aim of translation, cross-language validation and determination of psychometric properties of Urdu version of CES-DC for pediatric depression in Pakistan. Findings of pilot phase depicted good cross-language validation of the scale. The test-retest correlation between English and translated Urdu version was found to be significant $(\mathrm{r}=0.99)$. These findings are consistent with previous studies which reported good psychometric properties of scale ranging from 0.71 to 0.91 .15 Similar study has been carried by Li, Chung and Ho (2009) in China on 313 primary school students between the ages of 8 and 12 years old. Results showed that Chinse version of scale demonstrated adequate internal consistency, good content validity and appropriate convergent and discriminant validity. The scale has also showed strong test-retest reliability with coefficients ranging from 0.70 to $0.85 .{ }^{16}$

The findings of main phase revealed that Urdu version of scale has good internal consistency. The Cronbach alpha of the CES-DC in the present study was 0.78 for the total CES-DC score. These results are in harmony with the English version of the scale and the validations studies carried out in various other countries which indicated acceptable to good internal consistency in children. ${ }^{10,16,17}$ One study on the development of the French version of CESD of was done by Fuhrer et al. Results of preliminary investigations on sensitivity and specificity of the instrument performed on 33 hospitalized patients, 112 outpatients, and 5,226 patients consulting general medical doctors are summarized and provide the evidence for its reliability and validity. ${ }^{17}$

Further to it, the item-total correlation value must be positive and above 0.20 or even 0.30 . In our study, item-total correlation of most of the items of CESDC-U were in the range of .04 to .58 , which was acceptable. ${ }^{18}$ However, two items fitem no 4 (I felt like I was just as good as other kids) and 8 (I felt like something good was going to happen.)\} had less than 0.3 item -total correlations.

It can be inferred that children did not fully understand these items. Ideally, in such situations researcher should modify or remove such items. For this purpose, advance analysis such as confirmatory Factory analysis (CFA) and discussion with subject matter experts is recommended. Researcher conducted committee of SME again and discussed these items with them. They suggested to retain these items on the basis of their significance in relation to construct.

Beside the translation, cross- language validation and establishing reliability; determination convergent validity of Urdu version of CES-DC with SDQ-U was also the objective of this study. Results regarding the correlations of Urdu version of CES-DC and scores on emotional symptoms subscale of SDQ provided some evidence for convergent validity. These findings were 
in line with the previous studies.4,15,19,20 According Tsocheva et al, the psychometric properties of the Bulgarian version of the CES-DC on a sample of 700 (323 females, 377 males) adolescents, aged 13-17 years were satisfactory to good. The CES-DC significantly correlated with SDQ total scores and its subscales, indicating that a high level of depressive symptoms was associated with high level of emotional and behavioral problems. ${ }^{4}$ Overall findings related to correlation might provide evidence for the convergent validity of the Urdu version of the scale. The present study is the first attempt to examine the psychometric properties of the CES-DC in a primary school student population in Pakistan. As such, the results are best considered as preliminary research in the process of establishing cross-cultural equivalency of the scale.

\section{ACKNOWLEDGMENT}

Successful completion this research study was made possible with efforts and help of many people around us who deserve special thanks. First of all, this all was possible because of continuous support by our family members. Secondly, we would like to pay our thanks to all individuals who participated in this study.

\section{STUDY LIMITATIONS}

Small sample from one study site might limit the generalizability of these findings. However, further studies with more demographically diverse population from different areas of Pakistan would validate the findings of this study. Another shortcoming was the usage of self-report measure only. Though, these have been proven to have strong psychometric properties for children of 8 years and above. Still, the use of multiple-informant method would be more informative and recommended for future studies. Because of limited sample size, factor structure of CES-DC was not explored. So, it is recommended to carryout CFA with larger sample size for construct validity.

\section{CONCLUSION}

CESD-U is an easy, valid and reliable instrument to screen depression among Urdu speaking pediatric population. Therefore, it is recommended to use CESD-U in both clinical practice and future researchers among Pakistani children.

\section{Conflict of Interest: None. \\ Disclaimer}

Present study was conducted as part of $\mathrm{PhD}$ thesis.

\section{Author's Contribution}

NM: Conceptualized the study along with data collection, analysis/interpretation and drafting the manuscript, AM: Supervised the study with the provision of the critically reviews of the final manuscript.

\section{REFERENCES}

1. World Health Organization (WHO). Depression. Available at: https://www.who.int/news-room/fact-sheets/detail/depression [Accessed on September 2, 2021].

2. George MJ, Russell MA, Piontak JR, Odgers CL. Concurrent and subsequent associations between daily digital technology use and highrisk adolescents' mental health symptoms. Child Dev 2018; 89(1): 7888.

3. Schimmenti A, Bifulco A. Linking lack of care in childhood to anxiety disorders in emerging adulthood: the role of attachment styles. Child Adolesc Ment Health 2015; 20(1): 41-48.

4. Tsocheva I, Uzun B, Essau CA. Psychometric properties of centre for epidemiologic studies depression scale for adolescents in Bulgaria. Eur J Investig. Health Psychol Educ 2018; 8(1): 53-64.

5. Voltas N, Hernández-Martínez C, Arija V, Canals J. The natural course of anxiety symptoms in early adolescence: Factors related to persistence. Anxiety Stress Coping 2017; 30(6): 671-686.

6. Ahlen J, Lenhard F, Ghaderi A. Universal prevention for anxiety and depressive symptoms in children: A meta-analysis of rando-mized and cluster-randomized trials. J Prim Prev 2015; 36(6): 387-403.

7. Zafar S, Johar N, Haseeb F, Azam N, Mahmood H, Pervaiz F. Prevalence of socio-emotional problems in school-aged adole-scents of army public schools of Rawalpindi. Pak Armed Forces Med J 2019; 69 (Suppl-2): S181-S186.

8. Shafiq F, Haider SI, Ijaz S. Anxiety, depression, stress, and decisionmaking among orphans and non-orphans in Pakistan. Psychol Res Behav Manag 2020; 13(1): 313-318.

9. Tatar A, Kayiran SM, Saltukoglu G, Ozkut ES, Emeksiz M. Analysis of the center for epidemiologic studies depression scale (CES-D) in children and adolescents from the perspective of the item response theory. J Clin Psychopharmacol 2013; 23(3): 242-253.

10. Dershem LD, Patsiorkovski VV, O'Brien DJ. The use of the CES-D for measuring symptoms of depression in three rural Russian villages. Soc Indic Res 1996; 39(1): 89-108.

11. Hambleton RK, Patsula L. Increasing the validity of adapted tests: Myths to be avoided and guidelines for improving test adaptation practices. J Appl Test Technol 1999; 1(1): 1-13.

12. Weissman MM, Orvaschel H, Padian N. Children's symptom and social functioning self-report scales: Comparison of mothers' and children's reports. J Nerv Ment Dis 1980; 168(12): 736-740.

13. Goodman R. The strengths and difficulties questionnaire: a research note. J Child Psychol Psy 1997; 38(5):581-586.

14. Essau CA, Qadir F, Maqsood A, Sahar N, Bukhtawer N. Factor structure of the urdu version of the strengths and difficulties questionnaire in Pakistani adolescents. Acta Psychopathol 2017; 3(1): 10.

15. Choudhry FR, Al-Worafi YM, Akram B, Ahmed MA, ul-Haq MA, Khan TM, et al. Factor structure of urdu version of the flourishing scale. Front Psychol 2018; 9(1): 1513.

16. Li HCW, Chung OKJ, Ho KY. Center for epidemiologic studies depression scale for children: psychometric testing of the chinese version. J Adv Nurs 2010; 66(11): 2582-2591.

17. Fuhrer R, Rouillon F. La version francaise de l'echelle CES-D (center for epidemiologic studies-depression scale). description et traduction de l'echelle d'autoevaluation. [The French version of the CES-D (Center for Epidemiologic Studies Depression Scale]. Eur Psychiatry 1989; 4(3): 163-166.

18. d-Vaus D. Surveys in Social Research $5^{\text {th }}$ ed. Routledge 2002, Available at: https://www.taylorfrancis.com/books/mono/10.4324 /9780203501054/surveys-social-research-david-de-vaus

19. Essau CA, Creswell C, Waite P, Cooper PJ. Assessment and management of anxiety disorders in children and adolescents. Arch Dis Child 2014; 99(7): 674-678.

20. Cunningham NR, Ollendick TH. Comorbidity of anxiety and conduct problems in children: Implications for clinical research and practice. Clin Child Fam Psychol Rev 2010; 13(4): 333-347. 